\title{
Impacts of Personalized Sensor Feedback Regarding Exposure to Environmental Stressors
}

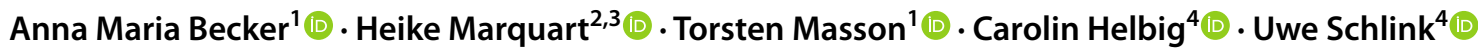

Accepted: 12 November 2021 / Published online: 28 December 2021

(c) The Author(s) 2021

\begin{abstract}
Feedback on personal exposure to air pollution, noise or extreme temperatures through wearable sensors or sensors installed at home or in the workplace can offer information that might motivate behaviours to mitigate exposure. As personal measurement devices are becoming increasingly accessible, it is important to evaluate the effects of such sensors on human perception and behaviour. We conducted a systematic literature research and identified 33 studies, analysing the effects of personal feedback on air pollution, noise and temperatures. Feedback was given through reports including different forms of visualization, in-person or over the telephone, or directly on the sensor or through a phone app. The exposure feedback led to behaviour changes particularly for noise and temperature feedback while findings on behaviour adaptation to avoid air pollution were mixed. Most studies reported increased awareness and knowledge from receiving exposure feedback. Many participants in studies on air pollution reported low levels of self-efficacy regarding exposure mitigation. For a better understanding of the effects of personal exposure feedback, more studies are required, particularly providing feedback from wearable sensors measuring outdoor air pollution, noise and temperature.
\end{abstract}

Keywords Feedback $\cdot$ Air pollution $\cdot$ Noise $\cdot$ Temperature $\cdot$ Personal sensor $\cdot$ Wearables

\section{Introduction}

Urban environmental hazards of highest concern for public health are airborne particulate matter [1], noise (especially from roads, rail, air traffic, industries) $[1,2]$ and the urban heat island effect that worsens thermal comfort in cities [3, 4]. Besides implementing policy changes (e.g. directives for

This article is part of the Topical Collection on Air Pollution

Anna Maria Becker

anna.becker@uni-leipzig.de

Uwe Schlink

Uwe.schlink@ufz.de

1 Department of Social Psychology, Institute for Psychology, Leipzig University, Leipzig, Germany

2 Institute of Transport Research, German Aerospace Center (DLR), Berlin, Germany

3 Geography Department, Humboldt University Berlin, Berlin, Germany

4 Department of Urban Environmental Sociology, Helmholtz Centre for Environmental Research - UFZ, Leipzig, Germany air quality [5] and noise [6]) individuals can mitigate their exposure through choosing less polluted routes or adapting behaviours in their household. In order to adapt, individuals need to know their level of exposure. This has become easier in recent years by the dissemination of personal sensors that are installed at home or in the workplace or by wearable sensors (wearables), which individuals can carry during everyday activities. In recent years, there has been an increasing number of studies using wearables [7]. Not only can these capture exposure patterns (exposome) [8], but they can also improve our knowledge of the distribution of pollutants in space and time.

Several studies have combined measured environmental data with questionnaires or interviews about the individuals' perceptions, experiences and beliefs regarding the environmental situation [9-16]. Some of these studies found that individual's exposure perception is not always in line with measured exposure data, highlighting the need to communicate exposure data back to individuals $[12,15,17$ for a review].

Feedback about personal environmental exposure can be provided at different levels of precision. It can be a general alert or forecast that affects a region or city or it can be 
personal feedback from wearables or sensors in people's workplace or household. This review focuses on personal feedback. Apart from personal feedback, there is some literature on the effects of regional air pollution or heat alerts [18-24]. Some alerts are bound to specific events such as smoke alerts due to wildfire $[25,26]$. These alerts can motivate protective behaviour such as drinking water and spending time in air-conditioned places [27] or reducing outdoor bicycle trips [28].

Wearables that provide direct feedback are increasingly accessible for private consumers (e.g. the Flow sensor ${ }^{1}$ ) and there is a growing interest in feedback from sensors installed in homes or at work. These developments make it important to question the feedback process and to summarize findings about its effectiveness in changing perceptions and behaviour. This review aims to analyse how personal feedback influences participants' perceptions of air pollution, noise, and temperatures and how it might motivate behaviours to mitigate exposure.

\section{Predicting (Health) Behaviour Change}

By using sensors that measure personal exposure to environmental stressors, people may encounter information, which they were previously not aware of and that may be framed in ways to increase their risk perceptions (exposure to air pollution, noise or heat is perceived as threatening, e.g., to health) and/or to elicit fear in them. Threat (fear) appeals are strong, when they communicate the negative consequences of an event or behaviour (e.g. smoking) as personally relevant and likely to occur [29]. Illustrating the severity of a behaviour's negative outcomes and the likelihood that the person will be affected, along with a suggestion of how to cope with the situation, can be an effective way to trigger behaviour change [29].

The effects of threat appeals to change people's health behaviour have been studied in the Health Belief Model (HBM) [30] and in the framework of Protection Motivation Theory (PMT) [31, 29]. Both theories were developed to address health-related behaviour change (e.g. stop smoking or exercising regularly) [29, 30, 32 and 33]. The HBM predicts behaviour change when the perceived susceptibility and severity of a negative health outcome are high and when actions to mitigate the harm are seen as beneficial [30]. On the other hand, perceived barriers to the beneficial behaviour can inhibit behaviour change [30]. Similarly, PMT predicts behaviour change, if current behaviour outcomes are perceived as harmful (threat appraisal) and the person sees

$\overline{1}$ https://plumelabs.com/en/flow/ him- or herself capable of implementing changes in their behaviour to avert the harm (coping appraisal) [31]. Fear was added as the emotional aspect of the threat appraisal [31]. The coping appraisal depends on two major factors: outcome efficacy (Is there an alternative behaviour that can substantially reduce the threat?) and self-efficacy (Can I implement these behaviour changes?) [31]. The coping appraisal also includes appraisals of the costs to perform protective behaviour, including aspects such as financial costs or the existence of strong behavioural habits decreasing the readiness for behaviour change [34, 35]. Meta-analytic evidence supports the feasibility of the PMT for explaining health behaviours [36]. Both the PMT and the HBM provide a well-established theoretical basis for the design of interventions (e.g., feedback interventions) aimed at changing health behaviours, such as behaviour targeting exposure mitigation. Other models to predict the formation of behavioural intentions such as the Theory of Planned Behaviour (TPB) [37] are less focused on the prediction of healthrelated behaviour, though keeping their framework in mind can also be of use to plan interventions. In particular, the Theory of Planned Behaviour posits that attitudes, perceived behavioural control, and subjective norms (the behaviour of important others) predict behavioural intentions [37].

Feedback and behavioural monitoring are important components of many behavioural interventions [38]. Interventions can entail feedback about a person's performance or behaviour as well as self-monitoring such as feedback to visualize physiological reactions (e.g., in fitness apps). Furthermore, feedback can include information on the behaviour of others, thereby giving a frame of reference and possibly activating a social norm (e.g., others are exposed to less particulate matter in the house). Social norms can be strong motivators of behaviour change [37]. We define feedback of environmental stressors as any form of information provided on personal exposure to air quality, noise or temperature. This can be understood as behavioural feedback because exposure levels can be a distal indicator of behaviours such as routing choices, indoor smoking, and cooking or voice levels. This behavioural feedback can have an effect on perceived outcome efficacy of different behaviours, if people can identify a relationship between their current behaviour and exposure levels. In turn, perceptions of efficacy are a crucial component of behaviour change theories (e.g., [31]). It can also be understood as an extended form of self-monitoring (similar to tracking apps that monitor the heart rate) as individuals receive information about their exposome [8]. This information about potentially harmful exposure levels can act as a threat appeal to motivate action [30] and motivate participants to adapt and optimize their individual exposure [39].

This review focuses on personal feedback on air quality, noise and temperature and aims to answer the following questions: 
Table 1 Search terms used in the systematic literature search

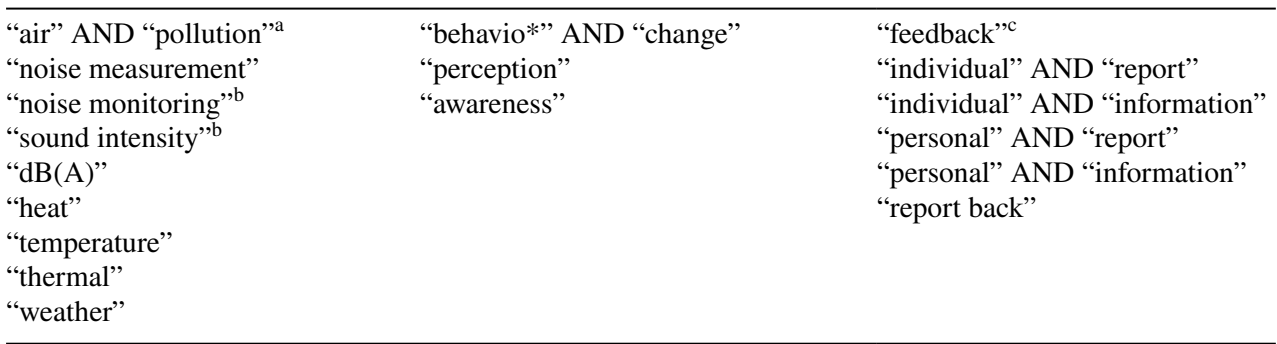

an Web of Science, the terms "air" and "pollution" were entered separately for most search rounds

bIn Scopus, the search terms "noise" and "sound" were entered as single search terms

"In Scopus, the term "feedback" was entered in conjunction with "individual" or "personal"
Q1.What impact does feedback on exposure to air pollution, noise and temperature have on participant's perceptions, emotions and behaviours?

Q2. Are there particular aspects of feedback provision that are particularly effective in changing behaviours?

Q3. Under which circumstances can environmental feedback lead to protective behaviour? What are aspects that might prevent behaviour change?

\section{Methods}

An initial non-structured literature search gave a rough overview of the literature available. Results were discussed to determine search terms for the structured literature search. Theses search terms were entered in two separate search engines: Scopus and Web of Science. The search terms were organized in three blocks: pollutants, dependent measures and form of feedback (Table 1). The search terms were combined to include one component of each block and all possible combinations were entered in Scopus and Web of Science.

The literature search yielded 5250 results in Web of Science and 3081 results in Scopus. In step one (see Fig. 1), we deleted duplets from the literature. At this stage, we included all papers in which feedback was given about air pollution, noise or temperature. Titles were excluded if they clearly referred to research outside the range of feedback on air quality, temperature or noise (e.g., biological and animal studies or robotics) or if they were review papers. Two authors then scanned the abstracts in step two. Papers were excluded if there was no indication of a feedback intervention, e.g., when studies examined only the association of exposure and perceptions (see [17] for a review) or health outcomes. In step three, all authors participated in reading the papers that were identified as relevant. In this round of reading the papers, we coded some aspects regarding the papers' methods and the form of feedback. To focus the scope of this review, we then limited our inclusion criteria to studies with personal feedback (e.g., wearables or sensors in the household or workplace). We did not consider studies with general pollution or heat alerts for a city or region. In this step, we added 8 papers from our initial unstructured literature search and reference lists. Figure 1 gives an overview of the literature reviewing process. We followed the PRISMA guidelines for structured literature reviews [40].

\section{Results}

\section{Descriptive Overview of the Reviewed Studies}

Thirty-three studies providing feedback on indoor and/or outdoor exposure to environmental stressors met our inclusion criteria (Table 2). Most studies were published in recent years (21 papers since 2018) and were conducted in the countries of the so-called global north (14 studies from the USA or Canada, 16 studies from European countries). The number of measurements or participants varied largely, ranging from one participant [39] to 38267 noise measurements [41]. Most of the studies targeted air pollution (22), while fewer studies gave feedback about noise (9), or temperatures (2).

For air pollution, most indoor studies dealt with indoor smoking (Fig. 2), including measurements of particulate matter (PM), radon, air nicotine and/or secondhand smoke. Other indoor studies on air pollution (e.g., from cooking stoves) measured $\mathrm{PM}, \mathrm{NO} 2, \mathrm{CO}, \mathrm{O} 3$, and VOCs. Outdoor studies on air pollution provided feedback from wearable sensors measuring PM, NO2, VOCs, black carbon, and NOx. Some studies gave feedback on participants' exposure indoors as well as outdoors. Most studies on noise exposure gave feedback about noise indoors, e.g., in the classroom [42-44] or a hospital [45-47]. These interventions aimed at lowering participants' voice, e.g., to protect the teacher's vocal health or intensive care patients. Studies on feedback of outdoor noise levels included interventions to promote hearing protection usage among air force workers [48] or farm workers [49]. The two studies on temperature gave 
Fig. 1 Flowchart of the literature search process [40]
Identification of studies
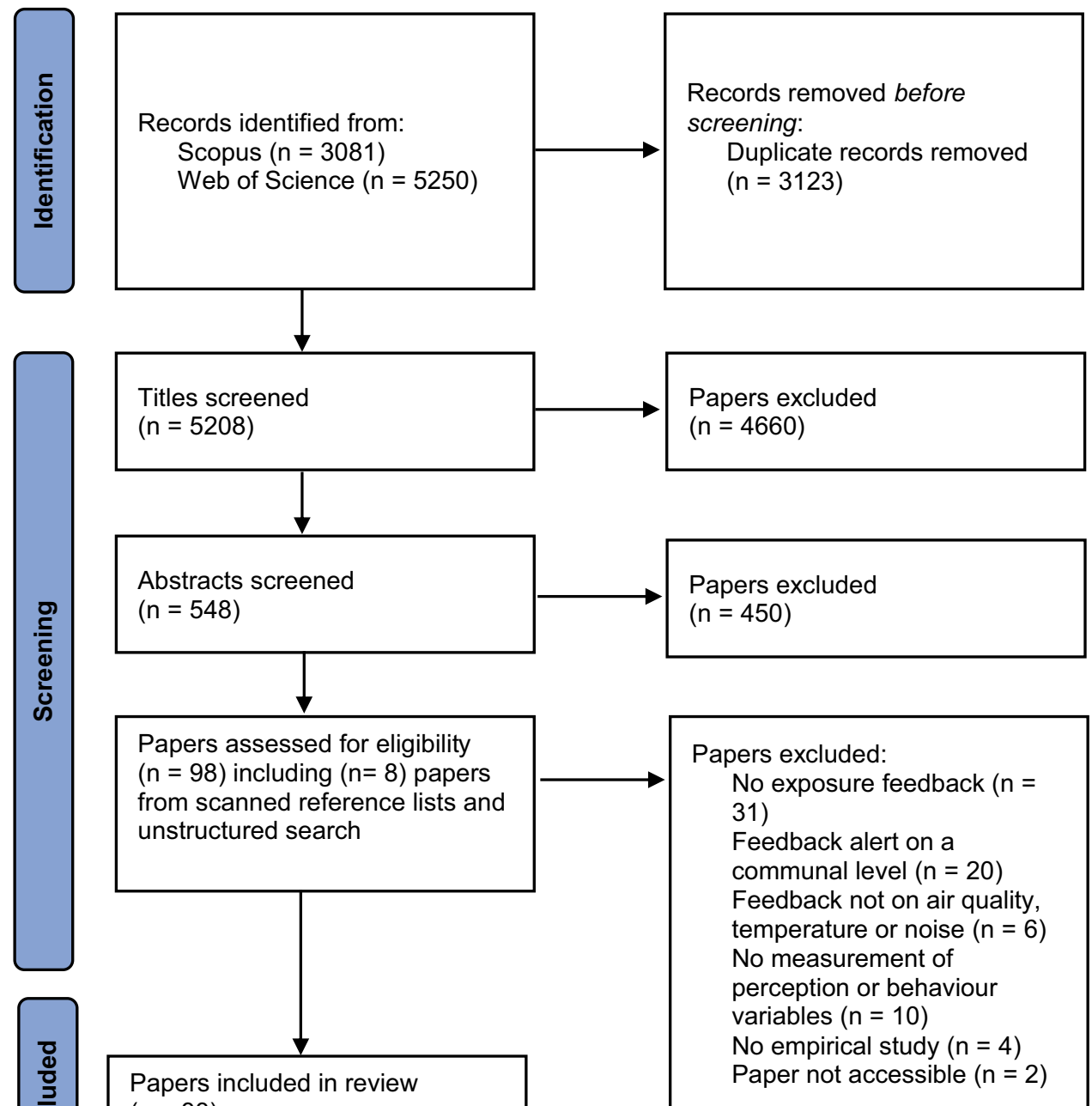

feedback on work-related outdoor heat [50] and cold temperatures [51].

\section{Design of the Feedback}

The reviewed studies varied significantly in their design of the feedback, involving differences in their feedback components and feedback frequency as well as the presentation and the medium of feedback information (Table 3 ).

\section{Feedback Components and Frequency of Feedback}

Studies differed with regard to their level of feedback, including feedback from wearable sensors (10 studies) or feedback on more aggregate levels of exposure, e.g., household or workplace-related exposure levels (22 studies). ${ }^{2}$ Wearable sensors enable participants to explore their environment by measuring their exposure in different locations and to protect themselves by avoiding highly polluted areas. Behaviour changes following feedback on more aggregate (e.g., household) levels of exposure to environmental stressors could also be motivated by the desire to protect vulnerable others from exposure, for example, protecting children from indoor smoking.

Providing information on how participants are able to change exposure levels can increase the effectiveness of feedback interventions, as behaviour suggestions can alter perceptions of self-efficacy, i.e., a person's beliefs in her/his capabilities to attain specific outcomes [52]. This

$\overline{2}$ One study did not provide details on the sensor [67]. 
Table 2 Descriptive overview of studies

\begin{tabular}{|c|c|c|c|c|c|c|}
\hline Paper & Year & Place & $\begin{array}{l}\text { Number of } \\
\text { participants }\end{array}$ & $\begin{array}{l}\text { Quantitative/ } \\
\text { Qualitative }\end{array}$ & $\begin{array}{l}\text { Idoor/ } \\
\text { Outdoor }\end{array}$ & Measured pollutant \\
\hline \multicolumn{7}{|c|}{ Studies on air pollution feedback } \\
\hline Borrelli et al. & 2010 & USA & 133 & Quantitative & Indoor & Secondhand smoke \\
\hline Adams et al. & 2011 & USA & $\begin{array}{l}32 \text { interviews (50 } \\
\text { households) }\end{array}$ & Qualitative & Mixed & 150 chemicals \\
\hline Klepeis et al. & 2013 & USA & 3 families & Mixed & Indoor & PM2.5 \\
\hline Hahn et al. & 2014 & USA & 50 & Quantitative & Indoor & $\begin{array}{l}\text { Radon, secondhand } \\
\text { smoke }\end{array}$ \\
\hline Borrelli et al. & 2016 & USA & 560 & Mixed & Indoor & Secondhand smoke \\
\hline Fang et al. & 2016 & Unclear & 3 families & Mixed & Indoor & PM \\
\hline Morgan et al. & 2016 & UK & $\begin{array}{l}9 \text { interviews ( } 39 \\
\text { participants) }\end{array}$ & Qualitative & Indoor & Air Quality Index \\
\hline Oltra et al. & 2017 & Spain & 28 & Qualitative & Mixed & $\mathrm{NO} 2$ \\
\hline $\begin{array}{l}\text { Haddad and de } \\
\text { Nazelle }\end{array}$ & 2018 & UK & 22 & Mixed & Outdoor & NO2, VOCs \\
\hline Varaden et al. & 2018 & UK & $\begin{array}{l}10 \text { using devices ( } 400 \\
\text { in survey) }\end{array}$ & Mixed & Outdoor & Black carbon \\
\hline Wong-Parodi et al. & 2018 & USA & $\begin{array}{l}4 \text { interviews }(60 \\
\text { participants) }\end{array}$ & Mixed & Indoor & PM2.5 \\
\hline Ratschen et al. & 2018 & UK & 205 & Quantitative & Indoor & PM2.5 \\
\hline Semple et al. & 2018 & UK & 117 & Quantitative & Indoor & PM2.5 \\
\hline Bales et al. & 2019 & USA & 29 & Qualitative & Mixed & $\begin{array}{l}\mathrm{CO}, \mathrm{NO} 2, \mathrm{O} 3 \text {, tem- } \\
\text { perature }\end{array}$ \\
\hline Hahn et al. & 2019 & USA & 515 & Qualitative & Indoor & Radon, air nicotine \\
\hline Tomsho et al. & 2019 & USA & 71 & Mixed & Indoor & $\mathrm{PM}, \mathrm{NO} 2$ \\
\hline Boso et al. & 2020 & Chile & 15 & Mixed & Indoor & PM \\
\hline Dobson et al. & 2020 & $\begin{array}{l}\text { Scotland, Greece, } \\
\text { Spain, Italy }\end{array}$ & 86 & Mixed & Indoor & PM2.5 \\
\hline $\begin{array}{l}\text { Heydon and } \\
\text { Chakraborty }\end{array}$ & 2020 & UK & 45 & Qualitative & Mixed & $\begin{array}{l}\text { PM 2.5, PM10, NOx, } \\
\text { VOCs }\end{array}$ \\
\hline Tan and Smith & 2020 & UK, Malaysia & 1 & Qualitative & Outdoor & $\begin{array}{l}\mathrm{PM} 2.5, \mathrm{PM} 10, \mathrm{NO} 2, \\
\text { VOC }\end{array}$ \\
\hline Mahjan et al. & 2020 & UK & $\begin{array}{l}4 \text { (10 participants } \\
\text { with sensors) }\end{array}$ & Qualitative & Mixed & $\mathrm{PM}$ \\
\hline O'Donnell et al. & 2020 & UK & $\begin{array}{l}15 \text { interviews ( } 120 \\
\text { participants) }\end{array}$ & Qualitative & Indoor & PM 2.5 \\
\hline \multicolumn{7}{|c|}{ Studies on noise feedback } \\
\hline Becker et al. & 2013 & UK, Italy, Belgium & 38,267 measurements & Quantitative & Mixed & Noise \\
\hline Wang et al. & 2014 & Canada & Unclear & Quantitative & Indoor & Noise \\
\hline Williams et al. & 2015 & Australia & 85 & Quantitative & Outdoor & Noise \\
\hline Chawla et al. & 2017 & USA & 106 & Quantitative & Indoor & Noise \\
\hline Trawick et al. & 2019 & USA & 19 & Quantitative & Outdoor & Noise \\
\hline Di Blasio et al. & $2019 a$ & Italy & 7 teachers & Quantitative & Indoor & Noise \\
\hline Di Blasio et al. & $2019 b$ & Italy & 550 class hours & Quantitative & Indoor & Noise \\
\hline Ukegjini et al. & 2020 & Switzerland & 664 surgeries & Quantitative & Indoor & Noise \\
\hline Tabuenca et al. & 2021 & Spain & 198 & Quantitative & Indoor & Noise \\
\hline \multicolumn{7}{|c|}{ Studies on temperature feedback } \\
\hline Thompson et al. & 2018 & USA & 66 & Quantitative & Outdoor & Heat \\
\hline Nelson et al. & 2020 & USA & 44 & Quantitative & Outdoor & Cold \\
\hline
\end{tabular}




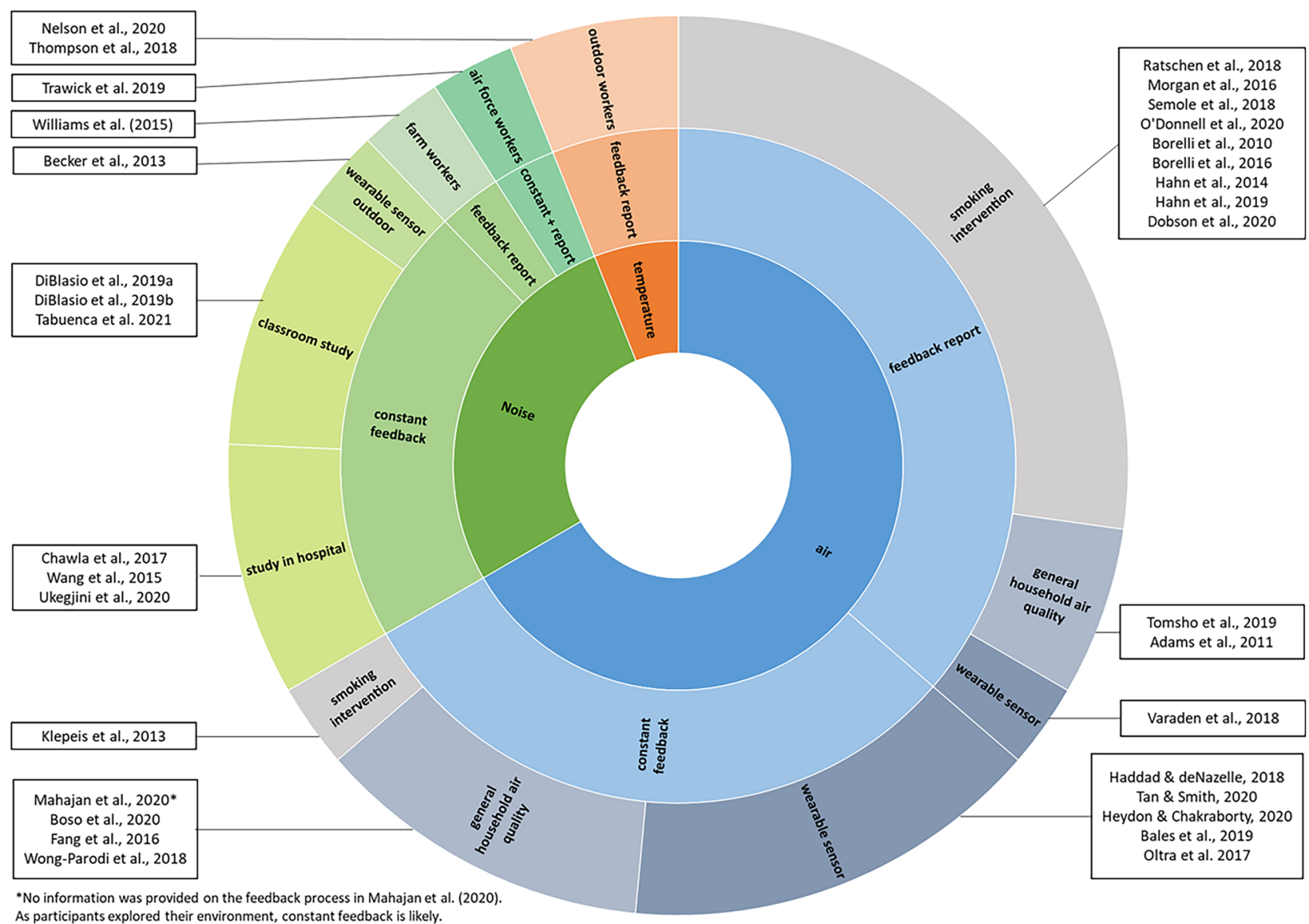

Fig. 2 Overview of studies

increased sense of self-efficacy can encourage behaviour change [31]. In contrast, providing threatening feedback information without actionable behaviour suggestions may be less effective or even backfire, leading to apathy or denial [53]. Whereas most of the air quality feedback studies also made suggestions for alternative behaviour to reduce indoor exposure (12 studies) or outdoor exposure (two studies), only one of the temperature feedback studies and only two noise feedback studies explicitly included suggestions on protection behaviour. For noise feedback, however, it is likely that teachers in the classroom requested pupils to lower their voice or that behaviours to reduce noise (i.e., lowering the voice) may be intuitive and not require a formalized suggestion.

Information on social comparisons can help participants to understand their exposure levels relative to the exposure of similar others or to gain information on what levels of exposure are rated as tolerable by their peer group (i.e., protection ingroup norms; [54]). In total, ten studies included elements of social comparison in their feedback, such as information on others' exposure, pollution levels in other places or by allowing participants to exchange their experiences in a chat group [55].
Regarding frequency of feedback, studies either provided their participants with continuous feedback (i.e., feedback anytime or on demand) or gave feedback only in intervals or at the end of the measurement phase. Continuous feedback enables participants to be more active in exploring their environment or observing how their behaviour affects exposure levels. Continuous feedback was more prevalent in air pollution (nine studies) and noise feedback studies (seven studies) as compared to temperature feedback studies (no studies).

\section{Presentation and Medium of Feedback Information}

Information on exposure levels may be easier to comprehend and, thus, may be more effective, depending on the presentation of the feedback $[56,57]$.

Feedback through an LED light or alert which indicates current pollution levels can be very intuitive and draw attention to high levels of exposure [58]. Few studies on air pollution (five studies) and none of the temperature studies used lights or auditory signals to indicate current levels of exposure. In contrast, most noise studies provided 
Table 3 Feedback components

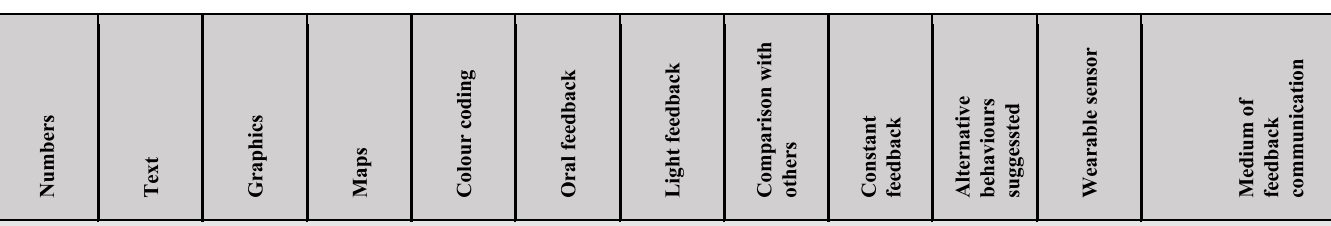

\begin{tabular}{|c|c|c|c|c|c|c|c|c|c|c|c|c|}
\hline \multicolumn{13}{|l|}{ Feedback on air pollution ${ }^{1}$} \\
\hline Haddad \& deNazelle (2018) & & & $\checkmark$ & & $\checkmark$ & & $\checkmark$ & ** & $\checkmark$ & $\checkmark$ & $\checkmark$ & sensor device/app \\
\hline Tan \& Smith (2020) & $\checkmark$ & & $\checkmark$ & $\checkmark$ & $\checkmark$ & & $\checkmark$ & & $\checkmark$ & & $\checkmark$ & sensor device/app \\
\hline Heydon \& Chakraborty (2020) & $\checkmark$ & & $\checkmark$ & $\checkmark$ & $\checkmark$ & & $\checkmark$ & & $\checkmark$ & & $\checkmark$ & sensor device/app \\
\hline Bales et al. (2019) & $\checkmark$ & & $\checkmark$ & $\checkmark$ & $\checkmark$ & & & & $\checkmark$ & & $\checkmark$ & App/webpage \\
\hline Oltra et al. (2017) & $\checkmark$ & & & & & & & & $\checkmark$ & & $\checkmark$ & sensor device \\
\hline Varaden et al. (2018) & $\checkmark$ & & $\checkmark$ & $\checkmark$ & $\checkmark$ & $\checkmark$ & & $\checkmark$ & & $\checkmark$ & $\checkmark$ & in Person \\
\hline Adams et al. (2011) & & $\checkmark$ & $\checkmark$ & & & & & $\checkmark$ & & & home & mail \\
\hline Boso et al. (2020) & & & & & & & Alert & $*$ & $\checkmark$ & & home & sensor device \\
\hline Fang et al. (2016) & $\checkmark$ & & $\checkmark$ & & $\checkmark$ & & & & $\checkmark$ & $\checkmark$ & home & app \\
\hline Tomsho et al. (2019) & $\checkmark$ & $\checkmark$ & $\checkmark$ & & & & & $* *$ & & $\checkmark$ & home & mail \\
\hline Wong-Parodi et al. (2018) & $\checkmark$ & & & & $\checkmark$ & & & & $\checkmark$ & $\checkmark$ & home & sensor device/online \\
\hline Borrelli et al. (2010) & & & & & & $\checkmark$ & & & & $\checkmark$ & home & in person \\
\hline Hahn et al. (2014) & & $\checkmark$ & & & & $\checkmark$ & & & & $\checkmark$ & home & telephone/mail \\
\hline Dobson et al. (2020) & $\checkmark$ & $\checkmark$ & $\checkmark$ & & & $\checkmark$ & & $\checkmark$ & & $\checkmark$ & home & in person/telephone/mail \\
\hline Borrelli et al. (2016) & & & & & & $\checkmark$ & & $\checkmark$ & & $\checkmark$ & home & in person \\
\hline Hanhn et al. (2019) & & & & & & $\checkmark$ & & & & $\checkmark$ & home & telephone \\
\hline Ratschen et al. (2018) & & & $\checkmark$ & & & $\checkmark$ & & & & $\checkmark$ & home & in person \\
\hline Morgan et al. (2016) & & & $\checkmark$ & & & $\checkmark$ & & & & $\checkmark$ & home & in person/telephone/mail \\
\hline Klepeis (2013) & & & $\checkmark$ & & & & $\checkmark$ & & $\checkmark$ & $\checkmark$ & home & computer screen \\
\hline Sempe et al. (2018) & $\checkmark$ & & $\checkmark$ & & & $\checkmark$ & & & & $\checkmark$ & home & in person \\
\hline O'Donnell et al. (2020) & & $\checkmark$ & $\checkmark$ & & & & & & & & home & unclear \\
\hline \multicolumn{13}{|l|}{ Feedback on noise } \\
\hline Trawick et al. (2019) & $\checkmark$ & & & & & & $\checkmark$ & & $\checkmark$ & $\checkmark$ & $\checkmark$ & sensor device, paper \\
\hline Wang et al. (2014) & & & & & $\checkmark$ & & $\checkmark$ & & $\checkmark$ & & hospital & sensor device \\
\hline DiBlasio et al. (2019a) & & & & & $\checkmark$ & & $\checkmark$ & & $\checkmark$ & & school & sensor device \\
\hline Chawla et al. (2017) & & & $\checkmark$ & & $\checkmark$ & $\checkmark$ & $\checkmark$ & & $\checkmark$ & & hospital & hallway and meetings \\
\hline DiBlasio et al. (2019b) & & & $\checkmark$ & & $\checkmark$ & & & & $\checkmark$ & & school & sensor device, teacher \\
\hline Tabuenca et al. (2021) & & & & & $\checkmark$ & & $\checkmark$ & & $\checkmark$ & & school & sensor device \\
\hline Becker et al. (2013) & $\checkmark$ & & $\checkmark$ & $\checkmark$ & & & & $\checkmark$ & $\checkmark$ & & $\checkmark$ & sensor device \\
\hline Williams et al. (2015) & & $\checkmark$ & & & & & & & & $\checkmark$ & farm & paper \\
\hline Ukegjini et al. (2020) & & & & & $\checkmark$ & & $\checkmark$ & & & & hospital & sensor device \\
\hline \multicolumn{13}{|l|}{ Feedback on temperature } \\
\hline Nelson et al. (2020) & $\checkmark$ & & & $\checkmark$ & & $\checkmark$ & & $\checkmark$ & & & $\checkmark$ & in person, paper \\
\hline Thompson et al. (2018) & $\checkmark$ & $\checkmark$ & $\checkmark$ & $\checkmark$ & & $\checkmark$ & & $* *$ & & $\checkmark$ & $\checkmark$ & in person, paper \\
\hline
\end{tabular}

* Exchange between participants was possible, ${ }^{* *}$ Participants received information about exposure in other places.

1) No information was provided on the feedback process in Mahajan et al. (2020).

feedback through a light. Colour coding can also help to visualize feedback information [59]. Colour coding was used to label exposure levels in graphs and maps for air pollution and in studies with light feedback (e.g., red light for high exposure).
Providing maps can be helpful for outdoor exposure measurements, as maps allow participants to locate their exposure and find ways to avoid it. Both temperature studies, most outdoor air pollution studies (four studies) and one noise study provided participants with maps, the latter 
being the only noise pollution study that did not measure exposure at work or in school. There were only two studies using wearable sensors that did not provide a map [48, 60].

Oral feedback (e.g., over telephone or in person) offers the opportunity for participants to interact and pose questions directly but may have the downside of being a "nonpermanent' form of communication. Relatively few studies provided oral feedback: these were mainly indoor smoking studies (combining feedback with efforts to increase respondents' self-efficacy), as well as one noise feedback study (discussing feedback during work meetings; [45]). Temperature feedback was given in feedback sessions where printed feedback reports were explained by the research team $[51,50]$.

\section{Method of Outcome Measurement}

Fifteen studies measured the effects of feedback quantitatively (Table 1), using questionnaires to assess changes in behavioural intentions or self-reported behaviour as well as sensor measurements to capture changes in participants' exposure levels (e.g., lower levels of indoor air pollution indicate less smoking; [25]). Sensor measurements capture changes in behaviour directly, while interview or questionnaire studies allow a more detailed investigation of factors possibly affecting exposure mitigation behaviours (e.g., perceived behaviour barriers). Although some studies relied solely on sensor measurements [42, 43, 45, 46 and 89] more studies combined sensor measurements with interviews [61, 62] or questionnaires [44, 48, 63 and 64]. Eight studies applied only qualitative methods (e.g., interviews, focus groups or analyses of journal entries [39, 55, 65-67]). Nine studies combined qualitative and quantitative methods to assess the outcome/s of exposure feedback (i.e., mixed methods approach) [62, 68-70]. Table 4 (Appendix) gives an overview of study outcomes and methods of outcome measurement.

\section{Behaviour Change as an Outcome}

\section{Behavioural Intentions and Self-reported Behaviour Change}

Changes in intentions or self-reported behaviour changes were observed in seven studies on indoor air pollution feedback and in five studies on outdoor air pollution feedback. Some participants intended to use outdoor air pollution feedback for long-term changes in the future [39, 69]. Selfreported behaviour changes included small-scale adaptations, such as opening windows at home, taking less polluted routes [39], getting out of the car in front of a bus rather than behind it or keeping car windows closed on busy highways [68]. In one study, $60 \%$ of participants reported having changed their behaviour to walking and cycling rather than taking a car to school [70]. However, in three studies, participants indicated that the wearable sensor did not motivate them to change their behaviour [60,65 and 69].

Participants who received feedback on indoor air pollution voiced their intention to make small-scale behaviour changes, such as reducing their use of pesticides, scented candles, bath soaps, and detergents and to increase ventilation $[71,72]$, or intentions to buy dry wood and to take part in a stove replacement program [55]. They also self-reported having made small behaviour changes such as using a vacuum cleaner, smoking outside or keeping doors closed to avoid outdoor pollution from entering the house [55]. In one study, where feedback included instant behavioural prompts, participants followed these suggestions [73]. However, in some studies the trend towards taking action was not significant [74].

In smoke cessation programs with exposure feedback, some persons reported willingness to make small behaviour changes, such as going outside to smoke, opening a window or door, and smoking less [75]. One study considered stages of behaviour change [64] and observed a progress towards exposure mitigation [64]. Self-reported behaviour changes included steps to mitigate smoking behaviour at home [61, 62 and 76]. However, these changes did not always sustain over time [61] and, while for some the feedback suggested a change, others ignored or denied the information [77] and some studies found that changes in self-reported smoking were not significant $[63,78]$.

Most studies with noise feedback focused on measured behaviour change, rather than intentions or self-reported behaviour. However, one study found that $95 \%$ of participants were motivated to use hearing protection in the future [49], while one study found that participants did not find the feedback helpful to change their behaviour during work [48]. Providing outdoor workers with information on cold or hot temperatures resulted in an increased willingness to adapt behaviour [50, 51].

\section{Changes in Manifest Behaviour}

Studies analysing actual changes in behaviour rely on sensor measurements to see whether exposure levels were reduced after participants received feedback. One study on general household air pollution showed no change in air quality after the feedback function of the sensor was activated [55], while another study which also included behavioural prompts in the feedback found a lower percentage of polluted time in the feedback phase [73].

Smoking cessation programs found mixed results regarding measured pollution levels. While some observed that the feedback led to a significant drop in PM2.5 levels [62, 89] others found no significant changes in PM [78] or no improvement through repeated feedback on secondhand 
smoke (vs. only one feedback) [61]. One study which compared smoking cessation interventions even found that an intervention with feedback to increase risk perception led to less decrease in secondhand smoke than a self-efficacy focused intervention without feedback [63].

Real-time feedback on noise exposure significantly decreased the noise level in hospitals [45, 46 and 47] and for air force workers experiencing continuous noise (but not for arms operators who experience impulse noise) [48]. Noise measurement devices in classrooms, indicating noise levels with colours and iconographs (smileys), resulted in a lower classroom noise level [42-44]. In one study, noisy classes had reversed effects because children tried to make loud sounds to keep the noise measurements up [44]. One study showed that users of an app measuring noise exposure changed their measurement behaviour, measuring more frequently in very noisy environments after receiving feedback on their personal noise exposure [41].

\section{Exchanging Information with Peers}

An important outcome of receiving exposure feedback was increased communication with peers about this issue. For example, respondents exchanged knowledge about air pollution by talking to others such as family and friends $[39,62,68,70,74$ and 80]. Some used the feedback to encourage others to quit smoking [77] or found it easier to communicate with their co-workers about hearing protection to mitigate noise exposure [49]. After receiving information on air pollution, participating schoolchildren even started a group initiative to reduce exposure to air pollution on school journeys [70]. Other participants showed more political activism against industry-related pollution [71]. Using sensors also led to curious observers, resulting in conversations with others [39, 74].

\section{Constraints to Behavioural Change}

Although receiving feedback was associated with positive outcomes, the studies also mentioned a number of constraints that limited behaviour change. Constraints related to outdoor air pollution exposure were that the capacity to choose less polluted routes was limited for practical reasons or because behaviour change was perceived as too costly [39, 60, 65 and 69]. In one study, participants reported that they were already doing their best to avoid air pollution [69]. Some participants in indoor air pollution studies felt that they had low levels of self-efficacy to control their indoor air pollution due to comfort constraints, weather conditions and lack of control over nearby polluters (e.g., emissions from neighbours) [55]. Others felt unsure how to reduce their exposure [71] or had family obligations, such as watching children, which did not allow them to smoke outside [62,
80]. Other reasons for not changing indoor smoking habits were bad weather or mental health problems [62].

\section{Other Outcomes}

Feedback on exposure also affected non-behavioural outcomes, including exposure-related knowledge, risk perception, emotions and confidence to mitigate exposure.

\section{Knowledge, Awareness and Risk Perception}

Personal feedback on air pollution and temperature increased participants' (self-reported) knowledge and problem awareness [39, 51, 55, 60, 62, 65-67, 70-74 and 80 and 90]. Participants also indicated an increased interest in air quality issues [68]. Specifically, respondents reported increased knowledge about the sources of air pollution and the level of exposure in different situations [67, 68, 72 and 73]. One noise-related study focused on the accuracy in perception and found that repetitive use of a noise feedback application led to more precise subjective perceptions of noise [41].

For some participants, the feedback increased their confidence, e.g., to talk to others about the topic or to reduce their exposure [39, 49, 73 and 74]. In other cases, however, participants reported that their increased awareness was uncomfortable due to feelings of powerlessness and low selfefficacy to control their exposure [65]. Apart from knowledge gains, receiving feedback about smoking at home and its health impacts also led to a significant increase in risk perception and concern regarding health impacts $[55,62$, 74 and 76$]$.

\section{Exposure-Related Emotions}

Many participants reported being surprised about their exposure to air pollution or cold temperatures $[51,55,60$, $65,68,71$, and 80]. One participant felt disappointment on days with high levels of air pollution [39]. One person reported sadness [66] and some reported fear in reaction to the feedback $[51,60]$. Heightened threat could also lead to feelings of powerlessness and resignation [65]. On the other hand, some participants found their experimentation with the sensors fun and informative [44, 68].

\section{Summary of Results}

The goal of this review was to investigate how pollution feedback can affect participants who receive information about their individual exposure levels. To answer our research questions regarding the effects of feedback on perceptions, emotions, and behaviour, it is helpful to differentiate the studies based on the source of pollution as well as the behaviours required to minimize exposure. Most outdoor air pollution 
studies, in which participants explored their surroundings with wearable sensors, found that alternative behaviours (i.e., choosing other routes) were very costly and change was often not possible. Results regarding behaviour change in response to indoor air pollution feedback were mixed. Though some found small-scale adaptations, there were also constraints to changing pollution levels. Noise feedback and feedback regarding ambient temperature were mostly successful in changing behaviour. Most studies raised awareness and knowledge about air pollution, noise or temperature. Several studies also reported that participants shared the new learned information with others. Several participants were surprised about their pollution levels and had a heightened perception of threat. Combined with feelings of low self-efficacy, this led to resignation for some participants.

\section{Discussion}

We have taken a closer look at a relatively new and evolving field, namely personal feedback on environmental stressors. As personal sensors are becoming more accessible, it is important to evaluate the effects of personal exposure feedback on human perception and behaviour. Our review shows that feedback can indicate behaviour change to some extent (Q1): Some studies observed behavioural changes or elicited intentions to change behaviour, while others did not change behaviour and some even led to resignation. Current studies in this field vary greatly in their study designs and methodologies of feedback provision and outcome measurement. Hence, this review will not be able to provide clear recommendations on how to design feedback to be successful (Q2), but we can draw attention to what has worked in the past and what has not; and we discuss some presumptions on why the results may vary $(\mathrm{Q} 3)$.

\section{There is a Lack of Feedback Studies on Outdoor Exposure}

It is encouraging to find that this field is evolving and many researchers are exploring the usefulness of wearable sensors. However, there are significant research gaps: surprisingly few studies focus on feedback regarding outdoor noise or outdoor air pollution and even after a thorough literature search, we found only two studies that provided temperature feedback. Noise is a severe environmental stressor in urban areas $[1,2]$ and traffic-related noise pollution is a major source of health problems [82]. Given its severity, there is a need to further investigate how noise exposure can be communicated outside of work/school during everyday activities (e.g., exposure to road/rail traffic noise during daily commute) [83]. Similarly, more studies on feedback about outdoor air pollution exposure in urban areas are needed, though research interests in this field are increasing [7]. Due to the fact that urban heat islands are threatening human health and comfort $[3,4]$, individual temperature feedback also deserves more attention in the future. While heat alerts and air pollution alerts are spread via media such as newspapers, TV or the radio [18-24] we see great potential for personal sensors in this field. Not only can wearable sensors provide information on the temporal and spatial distribution of pollutants; feedback from wearable sensors can also give more precise information about individual exposure patterns, which can inform behaviour change such as choosing different routes or travel times in everyday outdoor mobility.

\section{Self-efficacy Needs to Be Considered in Future Studies}

The results of this review imply that behaviour change for exposure mitigation is harder for air pollution than for noise exposure, even though most noise feedback interventions were rather simple (e.g., installing a feedback light). There may be different explanations for this. Noise reduction in indoor environments was mostly achieved by lowering voice levels. Participants themselves were the main source of noise, which means that they were mostly in control of noise levels. Control over the outcome, i.e., self-efficacy, is an important predictor in behaviour change theories such as the Protection Motivation Theory [29, 31] or the Theory of Planned Behaviour [37]. Investigating externally produced noise exposure and resulting mitigation behaviour would be an interesting future research direction.

Outdoor air pollution levels are not directly controllable and many participants felt like their capabilities to mitigate exposure were limited or too costly. While some implemented small-scale changes, others resigned. In studies where participants were given clear instructions on how to avoid air pollution [70,73] they felt more empowered and reported behaviour change. Smoking cessation programs were partly successful in leading participants to reduce smoking at home. Though smoking cessation is hard given the addictive properties of nicotine, this is again a case of the participant being the source of the pollution and therefore in control.

When participants did not feel in control of their exposure, some reported feeling resignation, fear or sadness. This hints at the dangers of interventions where participants receive information about their exposure, but do not get support in terms of clear behaviour recommendations. A lack of coping appraisal when threat appraisal is high can lead to so-called non-protective coping that is focused on reducing negative emotions when a threatening situation cannot be changed in itself [53]. These non-protective responses can be denial, wishful thinking, and resignation [53, 84]. Interventions without behavioural suggestions to increase self-efficacy might backfire and lead to frustration rather than problem-focused behaviour changes. 


\section{Collective Action as an Outcome}

Outdoor air pollution, noise, and rising temperatures are a collective problem. Since individuals find it difficult to avoid exposure, it is important to take collective reactions to environmental feedback into account $[85,86]$. Turning towards agentic groups can provide a feeling of group-based control [87] and therefore spur people into action. There are indications that participants have used their newly learned insights from the sensor measurements to talk to others and feedback even motivated political activism. Examining participants' willingness to take collective action or laying a stronger focus on communication aspects (e.g., platforms where participants can exchange experiences or get in contact with experts/decision-makers) would be an interesting research direction for exposure feedback studies.

\section{More Powerful Study Designs are Needed}

Finally, most of the reviewed studies are explorative or quasiexperimental (for example, looking at exposure levels and questionnaires before and after a feedback intervention). While these designs can help to get an initial understanding, they do not allow causal inferences. Therefore, it is important to use more rigorous testing (e.g., randomized controlled trials) in the future. Moreover, most studies are rather shortterm, highlighting the necessity for long-term studies to investigate how behaviour change can be sustained over time.

Furthermore, it is evident that most studies were conducted in the USA or Europe. This narrow focus can lead to conclusions that might be most applicable to WEIRD (white, educated, industrialized, rich and democratic) samples [88]. Further research is needed to test the applicability of these findings in different cultural settings and places where air pollution, noise or heat exposure may be an even more severe problem.

\section{Conclusion}

In this literature review we have investigated the impact of feedback from personal sensors measuring air pollution, noise, and temperature. Giving personal feedback has a great potential to increase knowledge and awareness of personal exposure. The reviewed studies show mixed results regarding behaviour change. The potential for a behaviour change depends not only on the form of feedback but also on the source of pollution and the type of behaviours required to mitigate exposure. Studies in which participants are in control of their exposure (e.g., their own noise emissions or smoking behaviour) more often lead to behaviour changes in response to feedback, than studies in which they receive feedback on exposure from external sources outside of their control (e.g., outdoor air pollution). When behaviour adaptations to avoid exposure are very costly or seem impossible, this can result in negative emotions or resignation.

Suggestions for future research directions in the field of individual feedback from sensors are as follows:

Firstly, personal feedback on outdoor exposure is rare, especially outdoor noise pollution, and extreme temperatures during daily activities are missing. Given their severity for health [1, 3 and 4], future research should investigate the effects of individual feedback during outdoor activities. Secondly, future studies should pay more attention to self-efficacy and take behavioural change models (e.g., Protection Motivation Theory [29, 31]) into account when designing the feedback process. The reviewed studies highlight the necessity of providing guidance on how to cope with exposure. This is important not only to motivate individual protective behaviour but also to avoid fear and resignation. Thirdly, communication with peers was an outcome in several studies on air pollution exposure. This exchange is important for people not only to understand their exposure in relation to others but also to feel empowered 
to take action as members of a group [85]. This aspect should be further studied in the context of personal exposure feedback. Finally, future research should focus on rigorous study designs such as randomized controlled trials and longitudinal studies.

Providing feedback on personal exposure to environmental stressors has a great potential to motivate behaviour adaptations and to raise awareness about the health impact of our surroundings. As personal sensor technology is becoming more accessible, this field of research is developing quickly and it offers a promising perspective for future health interventions and exposure communication.

Author Contribution All authors contributed to the design and implementation of the research, to the analysis of the results and to writing the manuscript.

Funding Open Access funding enabled and organized by Projekt DEAL. The research was supported by funding from DGF in VGI Science program project number 424979005.

Availability of Data and Material Not applicable.

Code Availability Not applicable.

\section{Declarations}

Conflict of Interest The authors declare no competing interests.

Open Access This article is licensed under a Creative Commons Attribution 4.0 International License, which permits use, sharing, adaptation, distribution and reproduction in any medium or format, as long as you give appropriate credit to the original author(s) and the source, provide a link to the Creative Commons licence, and indicate if changes were made. The images or other third party material in this article are included in the article's Creative Commons licence, unless indicated otherwise in a credit line to the material. If material is not included in the article's Creative Commons licence and your intended use is not permitted by statutory regulation or exceeds the permitted use, you will need to obtain permission directly from the copyright holder. To view a copy of this licence, visit http://creativecommons.org/licenses/by/4.0/.

\section{Appendix Impacts of personalized feedback regarding exposure to environmental stressors}

Table 4 Outcomes of reviewed studies (positive outcomes (green), negative outcomes (red), exchange with others (violet), awareness/ knowledge (blue), emotions (yellow))

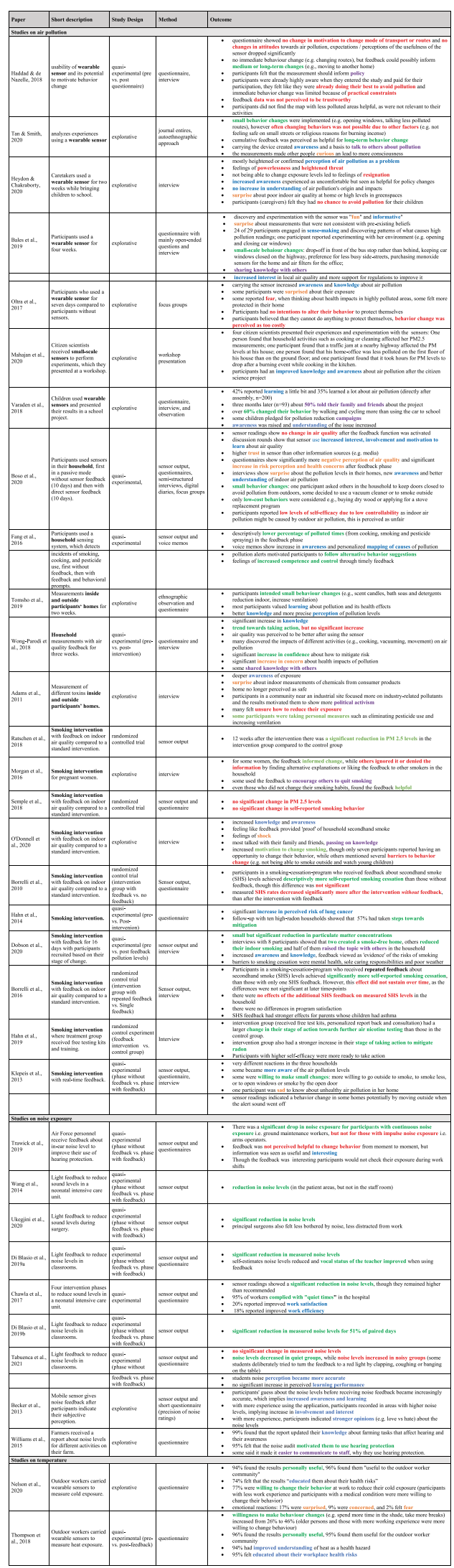




\section{References}

1. Hänninen O, Knol Anne B, Jantunen M, Lim TA, Conrad A, Rappolder M. Environmental burden of disease in Europe: assessing nine risk factors in six countries. Environ Health Perspect. 2014. https://doi. org/10.1289/ehp.1206154.

2. WHO. Environmental Noise Guidelines for the European Region, World Health Organization.2018. https://www.euro.who.int/en/ publications/abstracts/environmental-noise-guidelines-for-theeuropean-region-2018. Accessed 06 Aug 2021.

3. Gasparrini A, Guo Y, Hashizume M, Lavigne E, Zanobetti A, Schwartz J. Mortality risk attributable to high and low ambient temperature: a multicountry observational study. Lancet. 2015. https://doi.org/10.1016/S0140-6736(14)62114-0.

4. Parsons K. Human thermal environments: the effects of hot, moderate, and cold environments on human health, comfort, and performance. 3rd ed. Boca Raton: CRC Press; 2014.

5. EU. Council Directive 1999/30/EC of 22 April 1999 relating to limit values for sulphur dioxide, nitrogen dioxide and oxides of nitrogen, particulate matter and lead in ambient air. 1999. http:// eur-lex.europa.eu/LexUriServ/LexUriServ.do?uri=OJ:L:1999: 163:0041:0060:EN:PDF. Accessed 06 Aug 2021.

6. EU. Environmental Noise Directive END 2002/49/EC of the European Commission. 2002. https://data.consilium.europa.eu/doc/ document/ST-3611-2002-INIT/en/pdf. Accessed 06 Aug 2021.

7. Helbig C, Ueberham M, Becker AM, Marquart H, Schlink U. Wearable sensors for human environmental exposure in urban settings. Curr Pollut Rep. 2021. https://doi.org/10.1007/ s40726-021-00186-4.

8. Loh M, Sarigiannis D, Gotti A, Karakitsios S, Pronk A, Kuijpers E, Annesi-Maesano I, Baiz N, Madureira J, Fernandes EO, Jerrett M, Cherrie JW. How sensors might help define the external exposome. Int J Environ Res Public Health. 2017. https://doi.org/10.3390/ ijerph14040434.

9. Böcker L, Dijst M, Faber J. Weather, transport mode choices and emotional travel experiences. Transp Res A: Policy Pract. 2016. https://doi.org/10.1016/j.tra.2016.09.021.

10. Camusso C, Pronello C. A study of relationships between traffic noise and annoyance for different urban site typologies. Transp Res D: Transp. 2016. https://doi.org/10.1016/j.trd.2016.02.007.

11. Chow WT, Akbar SNABA, Heng SL, Roth M. Assessment of measured and perceived microclimates within a tropical urban forest. Urban For Urban Green. 2016. https://doi.org/10.1016/j. ufug.2016.01.010.

12. Gany F, Bari S, Prasad L, Leng J, Lee T, Thurston GD, Gordon T, Acharya S, Zelikoff JT. Perception and reality of particulate matter exposure in New York City taxi drivers. J Expo Sci Environ Epidemiol. 2017. https://doi.org/10.1038/jes.2016.23.

13. Marquart H, Ueberham M, Schlink U. Extending the dimensions of personal exposure assessment: a methodological discussion on perceived and measured noise and air pollution in traffic. J Transp Geogr. 2021. https://doi.org/10.1016/j.jtrangeo.2021.103085.

14. Nikolopoulou M, Kleissl J, Linden PF, Lykoudis S. Pedestrians' perception of environmental stimuli through field surveys: focus on particulate pollution. Sci Total Environ. 2011. https://doi.org/ 10.1016/j.scitotenv.2011.02.002.

15. Ueberham M, Schlink U, Dijst M, Weiland U. Cyclists' multiple environmental urban exposures-comparing subjective and objective measurements. Sustainability. 2019. https://doi.org/10.3390/ su11051412.

16. Von Szombathely M, Albrecht M, Augustin J, Bechtel B, Dwinger I, Gaffron P, Krefis AC, Oßenbrügge J, Strüver A. Relation between observed and perceived traffic noise and socio-economic status in urban blocks of different characteristics. Urban Sci. 2018. https://doi.org/10.3390/urbansci2010020.
17. Cori L, Donzelli G, Gorini F, Bianchi F, Curzio O. Risk perception of air pollution: a systematic review focused on particulate matter exposure. Int J Environ Res Public Health. 2020. https:// doi.org/10.3390/ijerph17176424.

18. Yoo G. Real-time information on air pollution and avoidance behavior: evidence from South Korea. Popul Environ. 2020. https://doi.org/10.1007/s11111-020-00368-0.

19. Wen XJ, Balluz L, Mokdad A. Association between media alerts of air quality index and change of outdoor activity among adult asthma in six states, BRFSS, 2005. J Community Health. 2009. https://doi.org/10.1007/s10900-008-9126-4.

20. Noonan DS. Smoggy with a chance of altruism: the effects of ozone alerts on outdoor recreation and driving in Atlanta. Policy Stud J. 2014. https://doi.org/10.1111/psj.12045.

21. Henry GT, Gordon CS. Driving less for better air: Impacts of a public information campaign. J Policy Anal Manag. 2003. https:// doi.org/10.1002/pam.10095.

22. Lyons RA, Rodgers SE, Thomas S, Bailey R, Brunt H, Thayer D, Bidmead J, Evans BA, Harold P, Hooper M, Snooks H. Effects of an air pollution personal alert system on health service usage in a high-risk general population: a quasi-experimental study using linked data. J Epidemiol Community Health. 2016. https://doi.org/ 10.1136/jech-2016-207222.

23. Wang F, Zhao H, Zhang X, Niu C, Ma J. Understanding individual-level protective responses to air pollution warning: a case study of Beijing. China Hum Ecol Risk Assess. 2018. https://doi. org/10.1080/10807039.2018.1468995.

24. Williams S, Hanson-Easey S, Nitschke M, Howell S, Nairn J, Beattie C, Wynwood G, Bi P. Heat-health warnings in regional Australia: examining public perceptions and responses. Environ Hazards. 2019. https://doi.org/10.1080/17477891.2018.1538867.

25. Rappold AG, Hano MC, Prince S, Wei L, Huang SM, Baghdikian C, \& Hubbell B. Smoke sense initiative leverages citizen science to address the growing wildfire-related public health problem. GeoHealth. 2019. https://doi.org/10.1029/2019GH000199.

26. Hano MC, Prince SE, Wei L, Hubbell BJ, Rappold AG. Knowing your audience: a typology of smoke sense participants to inform wildfire smoke health risk communication. Front public health. 2020. https://doi.org/10.3389/fpubh.2020.00143.

27. Mehiriz K, Gosselin P, Tardif I, Lemieux MA. The effect of an automated phone warning and health advisory system on adaptation to high heat episodes and health services use in vulnerable groupsevidence from a randomized controlled study. Int J Environ Res Public Health. 2018. https://doi.org/10.3390/ijerph15081581.

28. Rabassa MJ, Grand MC, García-Witulski CM. Heat warnings and avoidance behavior: evidence from a bike-sharing system. Environ Econ Policy Stud. 2021. https://doi.org/10.1007/ s10018-020-00275-6.

29. Rogers RW. A protection motivation theory of fear appeals and attitude change. J Psychol. 1975. https://doi.org/10.1080/00223 980.1975.9915803.

30. Rosenstock IM. The Health Belief Model and preventive health behavior. Health Educ. Monogr. 1974. https://doi.org/10.1177/ 109019817400200405.

31. Maddux JE, Rogers RW. Protection motivation and self-efficacy: a revised theory of fear appeals and attitude change. J Exp Soc Psychol. 1983. https://doi.org/10.1016/0022-1031(83)90023-9.

32. Plotnikoff RC, Trinh L. Protection motivation theory: is this a worthwhile theory for physical activity promotion? Exerc Sport Sci Rev. 2010. https://doi.org/10.1097/JES.0b013e3181d49612.

33. Prentice-Dunn S, Rogers RW. Protection Motivation Theory and preventive health: beyond the Health Belief Model. Health Educ Res. 1986. https://doi.org/10.1093/her/1.3.153.

34. Klöckner CA. A comprehensive model of the psychology of environmental behaviour - a meta-analysis. Glob Environ Change. 2013. https://doi.org/10.1016/j.gloenvcha.2013.05.014. 
35. Matthies E, Klöckner CA, Preißner CL. Applying a modified moral decision making model to change habitual car use: how can commitment be effective? Appl Psychol. 2006. https://doi. org/10.1111/j.1464-0597.2006.00237.x.

36. Milne S, Sheeran P, Orbell S. Prediction and intervention in health-related behavior: a meta-analytic review of Protection Motivation Theory. J Appl Soc Psychol. 2006. https://doi.org/10. 1111/j.1559-1816.2000.tb02308.x.

37. Ajzen I. The theory of planned behavior. Organ Behav Hum Decis Process. 1991. https://doi.org/10.1016/0749-5978(91)90020-T.

38. Michie S, Richardson M, Johnston M, Abraham C, Francis J, Hardeman W, Eccles MP, Cane J, Wood CE. The behavior change technique taxonomy (v1) of 93 hierarchically clustered techniques: building an international consensus for the reporting of behavior change interventions. Ann Behav Med. 2013. https://doi.org/10. 1007/s12160-013-9486-6.

39. Tan SHA, Smith TEL. An optimal environment for our optimal selves? An autoethnographic account of self-tracking personal exposure to air pollution. Area. 2020. https://doi.org/10.1111/area. 12671.

40. Page MJ, McKenzie JE, Bossuyt PM, Boutron I, Hoffmann TC, Mulrow CD, et al. The PRISMA 2020 statement: an updated guideline for reporting systematic reviews. BMJ. 2021;372. https://doi.org/10.1136/bmj.n71.

41. Becker M, Caminiti S, Fiorella D, Francis L, Gravino P, Haklay M, Hotho A, Loreto V, Mueller J, Ricchiuti F, Servedio VDP, Sîrbu A, Tria F. Awareness and learning in participatory noise sensing. PLoS ONE. 2013. https://doi.org/10.1371/journal.pone.0081638.

42. Di Blasio S, Puglisi GE, Gervasi C, Castellana A, Murgia S, Minelli G, Vannelli G, Corbellini S, Carullo A, Astolfi A. A pilot study in primary school on the effect of a noise monitoring system with lighting feedback on teachers' voice parameters, noise levels and subjective assessments. 23rd International Congress on Acoustics. 9.-13. Sept. 2019a.

43. Di Blasio S, Vannelli G, Shtrepi L, Puglisi GE, Calosso G, Minelli G, Murgia S, Astolfi A, Corbellini S. Long-term monitoring campaigns in primary school: the effects of noise monitoring system with lighting feedback on noise levels generated by pupils in classrooms. Inter-noise and noise-con Congress and Conference Proceedings. 2019;259(5):4309-16.

44. Tabuenca B, Boerner D, Kalz M. Effects of an ambient learning display on noise levels and perceived learning performance in a secondary school. IEEE Trans Learn Technol. 2021. https://doi. org/10.1109/TLT.2021.3056038.

45. Chawla S, Barach P, Dwaihy M, Kamat D, Shankaran S, Panaitescu B, Wang B, Natarajan G. A targeted noise reduction observational study for reducing noise in a neonatal intensive unit. J Perinatol. 2017. https://doi.org/10.1038/jp.2017.93.

46. Ukegjini K, Kastiunig T, Widmann B, Warschkow R, Steffen T (2020). Impact of intraoperative noise measurement on the surgeon stress and patient outcomes. A prospective, controlled, single-center clinical trial with 664 patients. Surgery. 2020; https:// doi.org/10.1016/j.surg.2019.12.010 [Titel anhand dieser DOI in Citavi-Projekt übernehmen]

47. Wang D, Aubertin C, Barrowman N, Moreau K, Dunn S, Harrold J. Reduction of noise in the neonatal intensive care unit using sound-activated noise meters. Arch Dis Child Fetal Neonatal Ed. 2014. https://doi.org/10.1136/archdischild-2014-306490.

48. Trawick J, Slagley J, Eninger R. Occupational noise dose reduction via behavior modification using in-ear dosimetry among United States air force personnel exposed to continuous and impulse noise. Open Journal of Safety Science and Technology. 2019. https://doi.org/10.4236/ojsst.2019.92005.

49. Williams W, Brumby S, Calvano A, Hatherell T, Mason H, MercerGrant C, Hogan A. Farmers' work-day noise exposure. Aust J Rural Health. 2015. https://doi.org/10.1111/ajr.12153.
50. Thompson L, Sugg M, Runkle J. Report-back for geo-referenced environmental data: a case study on personal monitoring of temperature in outdoor workers. Geospat Health. 2018. https://doi. org/10.4081/gh.2018.629.

51. Nelson KB, Runkle JD, Sugg MM. Reporting back environmental health data among outdoor occupational workers in the cold season in North Carolina. USA Southeast Geogr. 2020. https://doi. org/10.1353/sgo.2020.0013.

52. Bandura A. The anatomy of stages of change. Am J Health Promot. 1997. https://doi.org/10.4278/0890-1171-12.1.8.

53. Rippetoe PA, Rogers RW. Effects of components of protectionmotivation theory on adaptive and maladaptive coping with a health threat. J Pers Soc Psychol. 1987. https://doi.org/10.1037/ 0022-3514.52.3.596.

54. Masson T, Fritsche I. Adherence to climate change-related ingroup norms: do dimensions of group identification matter? Eur J Soc Psychol. 2014. https://doi.org/10.1002/ejsp.2036.

55. Boso À, Álvarez B, Oltra C, Garrido J, Muñoz C, Hofflinger Á. Out of sight, out of mind: participatory sensing for monitoring indoor air quality. Environ Monit Assess. 2020. https://doi.org/ 10.1007/s10661-019-8058-z.

56. McCrudden MT, Rapp DN. How visual displays affect cognitive processing. Educ Psychol Rev. 2017. https://doi.org/10.1007/ s10648-015-9342-2.

57. Renkl A, Scheiter K. Studying visual displays: how to instructionally support learning. Educ Psychol Rev. 2017. https://doi.org/10. 1007/s10648-015-9340-4.

58. Kim M, Lee J, Lee H, Kim S, Jung H, Han KH. The color and blink frequency of LED notification lights and smartphone users' urgency perception. In: Stephanidis C, editor. HCI International 2014 - Posters' Extended Abstracts. Communications in Computer and Information Science, vol 435. Springer, Cham. 2014. https:// doi.org/10.1007/978-3-319-07854-0_107.

59. Ozcelik E, Karakus T, Kursun E, Cagiltay K. An eye-tracking study of how color coding affects multimedia learning. Comput Educ. 2009. https://doi.org/10.1016/j.compedu.2009.03.002.

60. Oltra C, Sala R, Boso À, Asensio SL. Public engagement on urban air pollution: an exploratory study of two interventions. Environ Monit Assess. 2017. https://doi.org/10.1007/s10661-017-6011-6.

61. Borrelli B, McQuaid EL, Tooley EM, Busch AM, Hammond SK, Becker B, Dunsiger S. Motivating parents of kids with asthma to quit smoking: the effect of the teachable moment and increasing intervention intensity using a longitudinal randomized trial design. Addiction. 2016. https://doi.org/10.1093/her/17.5.659.

62. Dobson R, O’Donnell R, Tigova O, Fu M, Enríquez M, Fernandez E, Carreras G, Gorini G, Verdi S, Borgini A, Tittarelli A, Veronese C, Ruprecht A, Vyzikidou V, Tzortzi A, Vardavas C, Semple S. Measuring for change: a multi-centre pre-post trial of an air quality feedback intervention to promote smoke-free homes. Environ Int. 2020. https://doi.org/10.1016/j.envint.2020.105738.

63. Borrelli B, McQuaid EL, Novak SP, Hammond SK, Becker B. Motivating Latino caregivers of children with asthma to quit smoking: a randomized trial. J Consult Clin Psychol. 2010. https:// doi.org/10.1037/a0016932.

64. Hahn EJ, Wiggins AT, Rademacher K, Butler KM, HuntingtonMoskos L, Rayens MK. FRESH: long-term outcomes of a randomized trial to reduce radon and tobacco smoke in the home. Prev Chronic Dis. 2019. https://doi.org/10.5888/pcd16.180634.

65. Heydon J, Chakraborty R. Can portable air quality monitors protect children from air pollution on the school run? An exploratory study Environ Monit Assess. 2020. https://doi.org/10.1007/ s10661-020-8153-1.

66. Klepeis NE, Hughes SC, Edwards RD, Allen T, Johnson M, Chowdhury Z, Smith KR, Boman-Davis M, Bellettiere J, Hovell MF. Promoting smoke-free homes: a novel behavioral intervention 
using real-time audio-visual feedback on airborne particle levels. PLoS One. 2013. https://doi.org/10.1371/journal.pone.0073251.

67. Mahajan S, Kumar P, Pinto JA, Riccetti A, Schaaf K, Camprodon G, Smári V, Passani A, Forino G. A citizen science approach for enhancing public understanding of air pollution. Sustain Cities Soc. 2020. https://doi.org/10.1016/j.scs.2019.101800.

68. Bales E, Nikzad N, Quick N, Ziftci C, Patrick K, Griswold WG. Personal pollution monitoring: mobile real-time air quality in daily life. Pers Ubiquit Comput. 2019. https://doi.org/10.1007/ s00779-019-01206-3.

69. Haddad H, de Nazelle A. The role of personal air pollution sensors and smartphone technology in changing travel behaviour. J Transp Health. 2018. https://doi.org/10.1016/j.jth.2018.08.001.

70. Varaden D, McKevitt C,Barratt B. Making the invisible visible: engaging school children in monitoring air pollution in London. Research for All. 2018. https://doi.org/10.18546/RFA.02.2.06.

71. Adams C, Brown P, Morello-Frosch R, Brody JG, Rudel R, Zota A, Dunagan S, Tovar J, Patton S. Disentangling the exposure experience: the roles of community context and report-back of environmental exposure data. J Health Soc Behav. 2011. https:// doi.org/10.1177/0022146510395593.

72. Tomsho KS, Schollaert C, Aguilar T, Bongiovanni R, Alvarez M, Scammell MK, Adamkiewicz G. A Mixed methods evaluation of sharing air pollution results with study participants via reportback communication. Intern J Environ Re Public Health. 2019. https://doi.org/10.3390/ijerph16214183.

73. Fang B, Xu Q, Park T, Zhang M. AirSense: an intelligent homebased sensing system for indoor air quality analytics. Proceedings of the 2016 ACM International joint conference on pervasive and ubiquitous computing. 2016. https://doi.org/10.1145/2971648. 2971720.

74. Wong-Parodi G, Dias MB, Taylor M. Effect of using an indoor air quality sensor on perceptions of and behaviors toward air pollution (Pittsburgh empowerment library study): Online survey and interviews. JMIR Mhealth Uhealth. 2018. https://doi.org/10.2196/ mhealth.8273.

75. Prochaska JO, Velicer WF. The transtheoretical model of health behavior change. Am J Health Promot. 1997. https://doi.org/10. 4278/0890-1171-12.1.38.

76. Hahn EJ, Rayens MK, Kercsmar SE, Adkins SM, Wright AP, Robertson HE, Rinker G. Dual home screening and tailored environmental feedback to reduce radon and secondhand smoke: an exploratory study. J Environ Health. 2014;76(6):156-61.

77. Morgan H, Treasure E, Tabib M, Johnston M, Dunkley C, Ritchie $\mathrm{D}$, Semple $\mathrm{S}$, Turner S. An interview study of pregnant women who were provided with indoor air quality measurements of second hand smoke to help them quit smoking. BMC Pregnancy Childbirth. 2016. https://doi.org/10.1186/s12884-016-1062-1.

78. Semple S, Turner S, O'Donnell R, Adams L, Henderson T, Mitchell S, Amos A. Using air-quality feedback to encourage disadvantaged parents to create a smoke-free home: results from a randomised controlled trial. Environ Int. 2018. https://doi.org/ 10.1016/j.envint.2018.07.039.

79. Prentice-Dunn S, McMath BF, Cramer RJ. Protection motivation theory and stages of change in sun protective behavior. J Health Psychol. 2009. https://doi.org/10.1177/1359105308100214.

80. O'Donnell R, Amos A, Turner SW, Adams L, Henderson T, Lyttle $\mathrm{S}$, Mitchell S, Semple S. 'They only smoke in the house when I'm not in': understanding the limited effectiveness of a smoke-free homes intervention. J Public Health. 2020. https://doi.org/10.1093/ pubmed/fdaa042.

81. Dupey LN, Smith JW. Close but no cigar: how a near-miss wildfire event influences the risk perceptions and mitigation behaviors of residents who experienced a recent, nearby wildfire. Institute of Outdoor Recreation and Tourism. 2019. https://digitalcommons. usu.edu/extension_curall/1959/. Accessed 06 Aug 2021.

82. Babisch W. Road traffic noise and cardiovascular risk. Noise health. 2008. https://doi.org/10.4103/1463-1741.39005.

83. Apparicio P, Gelb J. Cyclists' exposure to road traffic noise: a comparison of three North American and European cities. Acoustics. 2020. https://doi.org/10.3390/acoustics2010006.

84. Babcicky P, Seebauer S. Unpacking Protection Motivation Theory: evidence for a separate protective and non-protective route in private flood mitigation behavior. J Risk Res. 2019. https://doi. org/10.1080/13669877.2016.1147489.

85. Fritsche I, Barth M, Jugert P, Masson T, Reese G. A social identity model of pro-environmental action (SIMPEA). Psychol Rev. 2018. https://doi.org/10.1037/rev0000090.

86. Ottinger G. Buckets of resistance: standards and the effectiveness of citizen science. Sci Technol Hum Values. 2010. https://doi.org/ 10.1177/0162243909337121.

87. Fritsche I, Jonas E, Ablasser C, Beyer M, Kuban J, Manger AM, Schultz M. The power of we: evidence for group-based control. J Exp Soc Psychol. 2013. https://doi.org/10.1016/j.jesp.2012.07. 014.

88. Henrich J, Heine SJ, Norenzayan A. The weirdest people in the world? Behavioral and brain sciences. 2010. https://doi.org/10. 1017/S0140525X0999152X.

89. Ratschen E, Thorley R, Jones L, Breton MO, Cook J, McNeill A, Britton J, Coleman T, Lewis S. A randomised controlled trial of a complex intervention to reduce children's exposure to secondhand smoke in the home. Tob. Control. 2018. https://doi.org/10.1136/ tobaccocontrol-2016-053279.

90. Thompson L, Sugg M, Runkle J. Report-back for geo-referenced environmental data: a case study on personal monitoring of temperature in outdoor workers. Geospat. Health. 2018. https://doi. org/10.4081/gh.2018.629.

Publisher's Note Springer Nature remains neutral with regard to jurisdictional claims in published maps and institutional affiliations. 